\title{
Simple Phobia: Evidence for Heterogeneity
}

\author{
Joseph A. Himle, Kathleen McPhee, Oliver G. Cameron, and \\ George C. Curtis
}

Received Mav 18, 1988; revised version received November 8. 1988; accepted December 17, 1988.

\begin{abstract}
Although simple phobia is a residual category in $D S M-I I I$, clinical experience suggests at least four subtypes of this group. To test the validity of the subtypes, the authors compared patients with one of four simple phobias subtypes $(n$ : animal-insect $=25$, blood-injury $=9$, situational $=46$, chokingvomit $=8$ ). Significant sex differences were observed; all animal and insect phobics and seven of eight choking-vomit phobics were female, while the other two groups showed approximately equal numbers of males and females. Mean age of onset was significantly older for situational phobics than animal-insect or blood-injury phobics; choking-vomit probands were intermediate. Frequency of situational phobias differed significantly among relatives of the four proband groups, with highest frequency being found among situational probands. Thus, these clinical and epidemiological variables support the separation of simple phobia into at least these four diagnostic groups.
\end{abstract}

Key Words. Simple phobia, nosology, heterogeneity.

In DSM-III-R (American Psychiatric Association, 1987), simple phobia is a residual category of the phobic disorders; all phobias other than social phobia or agoraphobia are classified as simple phobias. The $D S M-I I I-R$ narrative refers to three types of simple phobia: fears of animals or insects, blood or injury, and situations including but not limited to heights or closed spaces. At least two observations support this division. First is the distinctive tendency of blood-injury phobics to vasovagal fainting on exposure to phobic stimuli (Thyer and Curtis, 1985; Thyer et al., 1985a). Second is the fact that phobias of heights, enclosures, crowds, driving, flying, and some social situations may occur either as apparently isolated symptoms or frequently as part of a wider panic-agoraphobia syndrome while phobias of animals, insects, blood, or injury rarely are associated with panic attacks or agoraphobia (Marks, 1987, p. 296). In the anxiety disorder research literature, the simple phobia diagnostic category is often used as a comparison group (Hallam and Hafner, 1978; Arrindell, 1980) to other anxiety disorder classifications, which would seem to imply that simple phobics are believed to be a homogeneous group of

Joseph A. Himle, A.C.S.W., is Clinical Social Worker, Anxiety Disorders Program; Oliver G. Cameron, M.D., Ph.D., is Associate Professor of Psychiatry, Director, Adult Outpatient Psychiatry, and Associate Director, Anxiety Disorders Program; and George G. Curtis, M.D., is Professor of Psychiatry, Chief, Adult Services, and Director, Anxiety Disorders Program, Department of Psychiatry, University of Michigan, Ann Arbor, MI. Kathleen McPhee, M.D., is Resident in Psychiatry, University of Massachusetts Medical Center. (Reprint requests to Mr. J.A. Himle, Dept. of Psychiatry, University of Michigan Hospitals, Ann Arbor, MI 48109-0705, USA.)

0165-1781/89/\$03.50 $\odot 1989$ Elsevier Scientific Publishers Ireland Ltd. 
patients with similar patterns of symptom development, clinical presentations, and responses to treatment, differing mainly in the object or situation that is feared. However, residual categories, by their very nature, bear a risk of containing heterogeneous groups. In fact, clinical impressions suggest differential rates of response of simple phobias to behavior therapy, with situational phobics being more resistant to treatment than other phobics. Situational phobics are more likely than animal and blood-injury phobics to report a history of "unpredictable" panic episodes (Marks, 1987, p. 296), suggesting that situational phobias may be related to the panic/agoraphobic syndrome. The research literature and the above-mentioned clinical impressions suggest that the $D S M-I I I-R$ residual group of phobic disorders may contain distinct phobic subtypes that have not been systematically studied. The present study compares four subgroups of the simple phobia diagnostic category.

\section{Methods}

Records of all patients evaluated in the University of Michigan Anxiety Disorders Clinic from 1978 to 1987 who received a sole diagnosis of simple phobia $(n=93)$ were reviewed. "Simple phobia" as an official diagnostic entity dates to 1980 with the publication of $D S M-I I I$ (American Psychiatric Association, 1980). Patients seen before DSM-III was adopted (approximately 25\%) were included if they received a single DSM-II (American Psychiatric Association, 1968) diagnosis of "phobia" or "phobic reaction" with a circumscribed focal phobia other than agoraphobia or what later came to be called "social phobia." Patients were not included if their anxiety or avoidance was accompanied by thought content or ritualistic behavior suggestive of obsessive-compulsive disorder. Patients seen after the publication of $D S M-I I /$ were diagnosed by $D S M-I I I$ criteria, including the exclusion criteria.

All evaluations were either performed by a faculty psychiatrist or by another clinician experienced in the diagnosis and treatment of anxiety disorders and reviewed by a faculty psychiatrist. Evaluations involved (1) one or more face-to-face interviews; (2) completion by patients of questionnaires designed to provide information relevant to anxiety disorders, affective disorders, psychosis, and a variety of other psychiatric symptoms; and (3) information provided from other sources such as past records. This evaluation procedure would identify most clinically significant psychiatric disorders, including after 1980 all $D S M-I I I$ defined anxiety, affective, and psychotic disorders. However, it would not necessarily exclude symptoms that were not severe enough to qualify for a diagnosis of a formal psychiatric syndrome (such as limited symptom altacks, before $D S M-I I I-R$ in 1987).

Each subject was categorized into one of four simple phobia subgroups: "animal-insect" $(n=25)$; blood-injury, "BI" $(n=9)$; "situational" $(n=46)$; and "choking-vomit" $(n=8)$. The situational group included those simple phobias commonly associated with agoraphobia, such as fears of crowded places, driving, buses, planes, heights, bridges, and elevators (Hallam and Hafner, 1978; Arrindell, 1980). The choking-vomit phobia group was composed of patients with fears of swallowing pills or food or with a pervasive fear of vomiting. Five patients with simple phobias that did not clearly fit into one of the subgroups were excluded from the study, including patients with fears of thunderstorms $(n=3)$, loud noises $(n=1)$, and swinging things $(n=1)$. Subjects' age of onset, gender, and simple phobia subtype were obtained from the interview summary and evaluation packet. Family history of phobias was also taken from the questionnaire packet; patients had been asked to give numbers of first-degree relatives with known fears of insects or animals; fears of blood, injury, surgery, or injections; fears of high places, enclosed places, or flying (equivalent to situational phobia); and fears of crowds, traveling, or being away from home (equivalent to agoraphobia). 


\section{Results}

Significant differences in age of onset and sex ratio were found between the four diagnostic subgroups. Mean age of onset was tabulated for each subgroup; situational $($ mean $=27.3$ years, $S D=14.3)$, animal-insect $($ mean $=14.9$ years, $S D$ $=12.9), \mathrm{BI}($ mean $=12.4$ years, $\mathrm{SD}=8.9)$, and choking-vomit $($ mean $=20.6$ years, $\mathrm{SD}=14.8$ ). By Kruskal-Wallis one-way analysis of variance (ANOVA) for ranks, an overall significant difference in onset age between groups was found (Kruskal-Wallis statistic $=17.94, d f=3, p=0.0005$ ). On the basis of pairwise Kruskal-Wallis analyses, this difference was found to lie mainly between the situational and animal group (14.29, $d f=1, p=0.0002)$, and the situational and BI group $(7.89, d f=1$, $p=0.005)$. Significant sex ratio differences were found between groups $\left(x^{2}=18.8\right.$, $d f=3, p=0.0003$ ). Overall, 62 females and 26 males were included in the study. A preponderance of females was found in the animal group, which contained only females $(n=25)$, and the choking-vomit group, with seven females and one male. The situational $($ male $=20$, female $=26)$ and $\mathrm{BI}($ male $=5$, female $=4$ ) groups were similarly distributed with approximately equal numbers of males and females. Pairwise $x^{2}$ tests indicated that the animal-insect phobic group had a significantly greater percentage of females than the situational $\left(\chi^{2}=15.13, d f=1, p=0.0001\right)$ and $\mathrm{BI}\left(x^{2}=16.28, d f=1, p=0.0001\right)$ groups.

One significant family history finding was observed. The number of first-degree relatives with situational phobias was highest among probands with situational phobias (mean number of relatives $=0.72$ ), lowest among probands with animal phobias (mean relatives $=0.06$ ), and intermediate in the other two groups $(\mathrm{BI}=0.40$ and choking-vomit $=0.25)($ Kruskal-Wallis statistic $=8.27, d f=3$, $p=0.04)$. The only significant pairwise comparison was for situational versus animal groups $(7.43, d f=1, p=0.006)$. The reported family history of other phobia subtypes did not differ significantly among the groups.

\section{Discussion}

As is sometimes true with clinic samples, these patients may not be representative of phobic individuals in the general population. Given this potential limitation, the data are consistent with the notion of at least four distinct phobia subtypes within the $D S M-I I I-R$ simple phobia category, exhibiting differences in age of onset and sex distribution. As presented in $D S M-I I I-R$, animal phobias begin most often in childhood, BI phobias begin most frequently in adolescence or early adulthood, and situational phobias begin later in life (American Psychiatric Association, 1987). According to $D S M-I I I-R$, simple phobias are more often diagnosed in women. Ost et al. (1984) found that BI phobias began most frequently in early childhood (mean onset age of 6.5 years) but that study excluded certain $\mathrm{BI}$ phobics on the basis of age and several medical conditions. An additional study of BI phobics by Thyer et al. (1985a) (whose sample included some subjects included in the present study) found $\mathrm{BI}$ phobias were as common in men as in women, and had a mean onset age ranging 
from childhood to adolescence. Marks and Gelder (1966) also reported mean onset ages of animal phobias (4.4 years) and specific situational phobias (22.7 years). Information regarding onset age among choking-vomit phobics and sex distribution among subtypes of simple phobias is not presented in the $D S M-I I I-R$ or in other research literature surveyed.

Our findings support $D S M-I I I-R$ in its conclusion regarding sex ratio and onset age among animal phobics, with a mean onset age of 14.9 years and exclusively female patients ( 25 of 25 ). This onset age is somewhat older than those previously reported but reflects the inclusion of one atypical case in this sample: an elderly woman was traumatized by a dog bite in her mid-sixties and subsequently developed a dog phobia. The exclusion of this case would have lowered our mean onset age for animal phobics to 12.8 years and further strengthened the onset differences found between subgroups.

None of the three other subtypes were represented by both a preponderance of women and an onset age in childhood. Age of onset in BI phobics was higher than the onset age found by Ost and associates (Ost et al., 1984) and was similar to the previous study by Thyer et al. (1985a). One patient included in the present study accounts, in part, for the higher mean onset age than that found by Ost et al. (1984). This subject reported the onset of BI phobia in his mid-thirties, while all other BI phobics reported age of onset before age 17.5. His exclusion would lower mean age of onset from 12.4 to 9.7 years and further enhance the onset differences discovered between simple phobia types. BI phobics were similar to animal phobics in onset age but differed in sex distribution with nearly equal numbers of male and female patients.

Mean onset age for the choking-vomit and situational phobic groups was from the late teens to late twenties, older than animal-insect or BI phobics; situational phobics were equally likely to be either male or female, while the choking-vomit group was predominantly female. Unique to the choking-vomit group, the distribution of age of onset did not have a distinct peak, but rather was flat, while the distributions for the other three groups were unimodal with relatively distinct peaks, suggesting that age of onset is not a specific characteristic of the choking-vomit group but is for the other three phobia subtypes.

These differences document heterogeneity of the four simple phobia subtypes. Five of the simple phobia patients omitted from the study did not fit neatly into any one of our subgroups, suggesting a possible need for other categories or a residual group. The findings related to the BI and the choking-vomit groups must be considered preliminary given the size of these subgroups.

One other finding was less conclusive but nonetheless suggested separation of the various subgroups. Although patient-reported retrospective family history data have well-known limitations (Weissman et al., 1986), it is of interest that the family history data in the present study revealed an increased incidence of situational phobias in first-degree relatives of situational probands. This difference was significant only with respect to animal-insect probands and not the other phobic subtypes. This finding further supports the contention of heterogeneity among simple phobia subgroups. 
The increased incidence of situational phobias in first-degree relatives of situational phobics provokes further speculation about the relationship of situational simple phobias to the panic/agoraphobic syndrome. The higher number of firstdegree relatives with situational phobias among situational probands suggests a similarity to the familial transmission of agoraphobia with panic attacks (Marks and Herst, 1970; Harris et al., 1983). It is appealing to hypothesize that a similar process plays a role in the development of situational simple phobia and agoraphobia with panic attacks.

It is also noteworthy that patients with panic disorder, although not immune from animal or BI phobias, do not appear to have any special disposition to develop them, whereas they do have a clear tendency to develop multiple situational phobias which often constitute the phobic component of agoraphobia with panic attacks (Hallam and Hafner, 1978; Arrindell, 1980). Thus, there is an association of fears of heights, closed spaces, crowds, driving, etc., with the agoraphobia syndrome. Additional support for panic/agoraphobia and situational simple phobias as aspects of relatcd disorders is found in comparing ages of onset. Mean age of onset in agoraphobia with panic attacks has been found to be the mid-twenties to late twenties (Sheehan et al., 1981; Thyer et al., 1985b; Cameron et al., 1986), very similar to that of the situational simple phobics (mean $=27.3$ years). In the present study, however, situational simple phobics were represented by approximately equal numbers of males and females as compared to the preponderance of females among agoraphobic patients (Robins et al., 1984; Marks, 1987). This finding suggests that men may be lcss likely than women to develop multiple phobic restrictions.

Although the association of situational simple phobia with the panic/agoraphobic syndrome is tentative, one finding remains clear: the data support significant differences among the four simple phobia subtypes studied. This may have important research and clinical implications. The present practice of viewing simple phobics as a homogeneous group may obscure potentially meaningful research findings in studies of simple phobia. By using the subtypes proposed here as separate simple phobia classifications, one may achieve more accurate and definitive research results.

Recognition of the simple phobia subtypes also has potential clinical implications for the selection of treatment strategies and anticipated treatment outcome. Given the proposed heterogeneity among subtypes, it is possible that simple phobics may respond differentially to therapeutic interventions, possibly requiring varying types and/or durations of treatment to achieve satisfactory results. Further studies of the classification, etiology, treatment, and outcome of simple phobia subgroups are needed.

\section{References}

American Psychiatric Association. DSM-II: Diagnostic and Statistical Manual of Mental Disorders. 2nd ed. Washington, DC: APA, 1968.

American Psychiatric Association. DSM-III: Diagnostic and Statistical Manual of Mental Disorders. 3rd ed. Washington, DC: APA, 1980.

American Psychiatric Association. DSM-III-R: Diagnostic and Statistical Manual of Mental Disorders. 3rd ed., revised. Washington, DC: APA, 1987. 
Arrindell, W.A. Dimensional structure and psychopathology correlates of the fear survey schedule (FSS-III) in a phobic population: A factorial definition of agoraphobia. Behaviour Research and Therapy, 18:229-242, 1980.

Cameron, O.G.; Thyer, B.A.; Nesse, R.M.; and Curtis, G.C. Symptom profiles of patients with $D S M-I I I$ anxiety disorders. American Journal of Psvchiatry, 143:1132-1137, 1986.

Hallam, R.S., and Hafner, R.J. Fears of phobic patients: Factor analyses of self-report data. Behaviour Research and Therapy, 16:1-6, 1978.

Harris, E.L.; Noyes, R., Jr.; Crowe, R.R.; and Chaudhry, D.R. Family study of agoraphobia: Report of a pilot study. Archives of General Psychiatry, 40:1061-1064, 1983.

Marks, I.M. Fears, Phobias and Rituals. London: Oxford Press, 1987.

Marks, I.M., and Gelder, M.G. Different ages of onset in varieties of phobia. American Journal of Psychiatry, 123:218-221, 1966.

Marks, I.M., and Herst, E.R. A survey of 1,200 agoraphobics in Britain. Social Psychiatry. 5:16-24, 1970.

Ost, L.G.; Sterner, U.; and Lindahl, I.L. Physical responses in blood phobics. Behaviour Research and Therapy, 22:109-117, 1984.

Robins, L.N.; Helzer, J.E.; Weissman, M.M.; Orvaschel, H.; Gruenburg, E.; Burke, J.D.; and Regicr, D.A. Lifetime prevalence of specific psychiatric disorders in three sites. Archives of General Psychiatry, 41:949-958, 1984.

Sheehan, D.V.; Sheehan, K.E.; and Minichiello, W.E. Age of onset of phobic disorders: A reevaluation. Comprehensive Psychiatry, 22:544-553, 1981.

Thyer, B.A., and Curtis, G.C. On the diphasic nature of vasovagal fainting associated with blood-injury-illness phobia. Pavlovian Journal of Biological Science, 20:84-87, 1985.

Thyer, B.A.; Himle, J.; and Curtis, G.C. Blood-injury-illness phobia: A review. Journal of Clinical Psychology, 41:451-459, 1985a.

Thyer, B.A.; Parrish, R.T.; Curtis, G.C.; Nesse, R.M.; and Cameron, O.G. Ages of onset of DSM-III anxiety disorders. Comprehensive Psychiatry, 26:113-122, $1985 \mathrm{~h}$.

Weissman, M.M.; Merikangas, K.R.; John, K.; Wickramaratne, P.; Prusoff, B.A.; and Kidd, K.K. Family-genetic studies of psychiatric disorders. Archives of General Psuchiatry, 43:1104-1115, 1986. 